\title{
Low-Carbon Development of the Construction Industry in China's Pilot Provinces
}

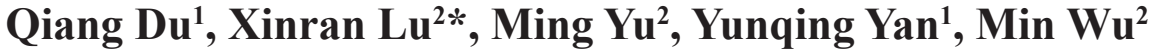 \\ 'School of Economics and Management, Chang'an University; Center for Green Engineering and Sustainable \\ Development, Middle Section of South Second Ring Road, Xi'an 710064, China \\ ${ }^{2}$ School of Civil Engineering, Chang'an University, Middle Section of South Second Ring Road, \\ Xi'an 710064, China
}

Received: 17 May 2019

Accepted: 26 August 2019

\begin{abstract}
The construction industry in China has developed rapidly. However, the development has been accompanied by a large amount of energy consumption and carbon emissions. Thus, the formulation of policies is complex, and research on the impact of emission reduction policies on carbon reduction in the construction industry, especially in China, has become necessary as it has massive regions with uneven development. Combined with the coefficient in the 2012 Intergovernmental Panel on Climate Change (IPCC) guidelines for national greenhouse gas inventories and China's calorific value, this study took the first batch of low-carbon pilot provinces (Guangdong, Hubei, Liaoning, Shaanxi, and Yunnan) announced by China's State Commission for Reform and Development in 2010 as the research object and separated the construction carbon emissions into direct and indirect categories to improve the accuracy of calculations at the provincial level. The EKC (environmental Kuznets curve) and Tapio model were employed to study the relationship between economic growth and carbon emissions of the construction industry, then the decoupling of major influencing factors of carbon emissions in the low-carbon pilot province in China from 2005 to 2014 based on the features of different regions and the economic policy planning in China were comparatively analyzed. The results showed that the construction industry carbon emissions and economic growth had a non-significant decoupling state in underdeveloped regions such as Shaanxi, Liaoning, and Yunnan, which would be better with low carbon development in potential, whereas they were significant decoupling states in well-developed regions such as Guangdong and Hubei. Then, this study revealed that the evolving trends of the decoupling of major influencing factors varied in different provinces; therefore, the results and insights support the policy and decisions to minimize construction carbon emissions.
\end{abstract}

Keywords: construction industry, carbon emissions, decoupling status, sustainable, China

*e-mail: lu_xinran@chd.edu.cn 


\section{Introduction}

The construction industry has grown greatly and developed in recent decades, which has influenced the development of China's economy. However, huge waste and pollution always inevitably happens at the same time due to the lack of technology and base equipment and other factors, which has led the development of the construction industry to be labeled as having high energy consumption and high pollution and high emissions. Research conducted by Chuai et al. [1] highlighted how carbon emissions from the construction industry made up $27.9 \%$ to $34.3 \%$ of the overall carbon emissions in China between 1995 and 2010. Carbon emissions are associated with the construction industry from some major phases, e.g., the material manufacture phase (such as the production of stone aggregates and cements), the construction phase (like the operation of construction equipment) and the operational phase [2]. Moreover, the construction industry is a carbon-intensive industry that consumes a considerable amount of energy from other industries. Reducing carbon emissions from the construction industry could significantly help China reach its lowcarbon sustainable development target. Therefore, to provide a basis for Chinese policymakers to formulate appropriate policies to reduce the industry-wide carbon emissions, it is important to accurately calculate the carbon emissions, identify the relationship between economic growth and carbon emissions, and the driving factors of the carbon emissions in the Chinese construction industry.

Many empirical studies that have discussed the relationships and linkages between economic growth, energy consumption, and environment pollution have been conducted in different regions [3-6]. However, it should be noted that the increase in China's national carbon emissions has been collectively shaped by the dynamics of emissions from all provinces, municipalities, and autonomous regions that comprise the country. Whether the increase in carbon emissions across various provinces can be effectively mitigated directly affects the achievement of the national emissions reduction targets. Moreover, China's provinces differ markedly in terms of economic development levels, industrial structures, energy consumption patterns, and many other factors. For example, while some provinces have entered the postindustrial age, others are experiencing an acceleration in the meta phase of industrialization [7]. Furthermore, there are some provinces whose industrial structures are dominated by high-tech and tertiary industries, whereas others remain heavily reliant on heavy industry $[8,9]$. Some provinces have gradually enhanced their levels of clean energy utilization, while others are still heavily dependent on coal consumption [10]. Hence, it is evident that a one-size-fits-all emissions reduction policy will not suffice to address the carbon emissions problem for all of China's provinces and regions. Studying the effectiveness of the existing provincial-level low-carbon policies is very important for China's future sustainable development.

The first batch of low-carbon pilot provinces: Guangdong, Hubei, Liaoning, Shaanxi and Yunnan were announced by China's State Commission for Reform and Development in 2010. They have different industry and energy systems and social-economic characteristics, and play an exemplary role in promoting low-carbon development [11-13]. This paper discusses the relationship between economic growth and carbon emissions and comparatively analyzes the decoupling of the major influencing factors of carbon emissions in the five low carbon pilot provinces from 2005 to 2014 in China based on the features of different regions and economic policy planning in China. The remainder of this paper is organized as follows: Section 3 shows the carbon emissions analysis model on the basis of the EKC approach, and the Tapio decoupling method is briefly presented. In Section 4, some results are analyzed regarding the carbon emissions characteristics of each pilot province. Conclusions and policy implications are summarized in Section 5.

\section{Literature Review}

Three main groups of researchers have examined the relationship between carbon emissions, energy consumption, and economic growth in the literature [14]. The first group, Grossman and Krueger [15], investigated the relationship between economic growth and environmental pollution using the urban area data of 42 countries. A second group of the extant literature have investigated the relationship between energy use and economic growth and presented distinct hypotheses [16]. For example, the unidirectional causality running from energy use to economic growth is called the growth hypothesis, which asserts that energy performs a key role in promoting economic activity and that a reduction in the energy supply will reduce economic growth [17, 18]. A third group of existing studies have inspected the dynamic relationships among carbon emissions, energy consumption, and economic growth. Ang [19] indicated that energy use and pollution are positively related to output in Malaysia; Zhang and Cheng [20] found that neither carbon emissions nor energy consumption promoted economic growth; Chindo et al. [21] examined Nigeria and investigated how energy consumption had a negative impact on GDP in the short run, while carbon emissions had a positive impact on GDP both in the long run and short run; Albiman et al. [22] investigated the dynamic relationship between environmental pollution, energy consumption and economic growth in Tanzania. However, their research focused on the description of a single relationship and did not reveal the relationship and effect of economic factors and carbon emissions in many ways. 
By consulting the above-published studies, EKC and decoupling are the two usual methods used at present. EKC is a method that can usually be used for examining economic growth and energy/emission intensity with curve fitting. Various shapes like the U-shape, inverted U-shape, and $\mathrm{N}$-shape refer to different relationships. Pak and Lee [23] examined an EKC hypothesis by analyzing the annual panel data of 16 metropolitan regions in Korea over a 16-year time period. The results showed that different pollutants, including $\mathrm{CO}, \mathrm{NO}_{2}$, and $\mathrm{SO}_{2}$, kept diverse linkages like dominant U-shape, region-specific U-shape, and potential $\mathrm{N}$-shape with GRDP separately. Liu [24] used the EKC and concluded that there was a lack of healthy environments to help society survive and develop as a result of humaninduced environmental degradation.

Decoupling is another method that is calculated with the growth rate of the economy and energy consumption or emission. In fact, decoupling was not initiated for the environment. The notion of decoupling was first applied to environmental studies in the 2000s. In 2002, the OECD started to present decoupling as one of the indicators [25] and thus decoupling was gradually regarded as an important conceptualization of economy-emission integration. Outstanding progress in decoupling was made by Vehmas et al. [26] and Tapio [27]. Based on the framework explaining different aspects of decoupling constructed by Vehmas et al., Tapio proposed eight logical possibilities to distinguish the decoupling state. After that, many studies covering decoupling-analysis can be found in various publications. For instance, Luken and Piras [28] conducted research on the decoupling of energy consumption and industrial output in the Asian region. Wang et al. [29] examined the decoupling indicators on carbon dioxide emissions and economic growth linkage using the whole case of Jiangsu (consisting of primary, secondary, and tertiary). Generally, eight kinds of measuring methods for decoupling exist.

In comparison with other methods, EKC and decoupling, with a more specific conception and less calculation, can be understood and operated in an easy way. More studies have adopted this model to analyze the relationships between the economy, energy use and carbon emissions from the industry perspective, such as manufacturing and transportation [30, 31]. Moreover, as a vital part of the secondary industry, the construction industry is one of the key industries contributing to carbon emissions in China. The discourse of the construction industry has always been related to more discourse of the relationship of economic growth from increasing environmental problems. As a result, the above two methods are quite fit for carbon emissions research in the construction industry, which is the topic of this paper. Through a literature review of carbon emissions studied in China, most researchers have conducted a total analysis [32-34] or focused on a particular region [35], but there was almost no attention paid to the relationship between related carbon emissions and economic growth at the provincial level based on low-carbon development policies.

Therefore, this study selected the EKC and Tapio model as the tools to investigate construction industry carbon emissions based on the calculation method of carbon emissions and the characteristics of the construction industry. We characterized the relationship between economic development and carbon emissions and comparatively analyzed the decoupling of the major influencing factors of carbon emissions in the low carbon pilot provinces from 2005 to 2014 in China, based on the features of different regions and economic policy planning. This paper comprehensively considered the carbon emissions characteristics and driving forces of the construction industry under the provincial lowcarbon policy, and tracked the implementation of existing policies.

\section{Methods \\ Calculating Construction Industry Carbon Emissions}

In this paper, construction industry carbon emissions were divided into two categories: (1) emissions that were directly generated by the construction industry; and (2) emissions from industries related to the construction industry. These industries include the mining and washing of coal, extraction of petroleum and natural gas, mining and processing metal ores, refining petroleum, coking and nuclear fuel processing, manufacturing raw chemical materials and chemical products, manufacturing non-metallic mineral products, smelting and pressing metals, and manufacturing metal products as well as transportation, storage, and postal services. The calculation process of direct carbon emissions of the construction industry is as follows:

$$
C_{D}=\sum_{i=1} E_{i} \times N C V_{i} \times A_{i} \times O_{i} \times 44 / 12
$$

...where $C_{D}$ denotes the direct carbon emissions of the construction industry; $i$ is the type of energy; $E_{i}$ represents the consumption of energy $I ; N C V_{i}$ represents the average lower-order calorific value of energy $I ; A_{i}$ is the carbon content per unit heat of energy $i$; $O_{i}$ represents the oxidation rate of energy $i$; and the figure is the molecular weight ratio of $\mathrm{CO}_{2}$ to carbon. The calculation of indirect carbon emissions from construction-related industries is usually divided into two steps. First, we selected nine industries related to the construction industry as above-mentioned. The equation for the industrial direct emissions is written as follows: 


$$
C_{D, j}=\sum_{i=1} E_{i, j} \times N C V_{i} \times A_{i} \times O_{i} \times 44 / 12
$$

...where $C_{D, j}$ denotes the direct carbon emissions consumed by industry $j$; and $\mathrm{E}_{i, j}$ represents the use of energy $i$ for industry $j$. Next, based on the input-output analysis, the construction industry indirect carbon emissions are calculated using the following equation:

$$
C_{I}=\sum_{j}\left(C_{D, j} / I O V_{j}\right) \times\left(C I O V / y_{j}\right)
$$

...where $C_{D, j}$ denotes the direct carbon emissions of industry $j ; j$ is the category of industries; $I O V_{j}$ refers to the total output values of industry $j ; C I O V$ represents the construction industry output values; and $y_{j}$ is the total consumption coefficient of industry $j$ from the construction industry, which can be derived from the input-output tables. Finally, the total carbon emissions of the construction industry are as follows:

$$
C_{T}=C_{D}+C_{I}
$$

This study then used the construction industry carbon intensity as the dependent variable, which included panel data of China's 30 provinces and municipalities from 2005-2014 (Hong Kong, Macao, Taiwan, and Tibet were not included due to a lack of data). The construction industry carbon intensity is defined as follows in Equation (5):

$$
\mathrm{CI}=\mathrm{C}_{\mathrm{T}} / \mathrm{CIOV}
$$

...where $C I$ represents the carbon intensity; $C I O V$ refers to the construction industry output values; and $C_{T}$ denotes the total construction industry carbon emissions.

\section{Environmental Kuznets Curve (EKC)}

EKC is the curve based on statistical real data, reflecting the relationship between carbon emissions and economic growth. According to earlier literature, this study established the EKC model of a carbon emissions environment in the construction industry, which explored the relationship between construction industry carbon emissions per capita and construction industry output values per capita:

$$
\ln C O_{2}=\alpha+\beta_{1} \ln I G D P+\beta_{2} \ln ^{2} I G D P+\beta_{3} \ln ^{3} I G D P+\mathcal{E}
$$

In the formula, $\alpha$ is the interception term; $\mathrm{CO}_{2}$ is the construction industry carbon emissions per capita; IGDP is the construction industry output values per capita; $\varepsilon$ is the random error term; and $\beta_{1}, \beta_{2}$, and $\beta_{3}$ are the parameters to be estimated. When we change the values of $\beta_{1}, \beta_{2}$, and $\beta_{3}$, the EKC curve showed different shapes:
(1) $\beta_{1}<0$ and $\beta_{2}=\beta_{3}=0$ signifies that the carbon emissions per capita of the construction industry decreased linearly with the increase of the output values per capita

(2) $\beta_{1}>0$ and $\beta_{2}=\beta_{3}=0$ signifies that the carbon emissions per capita of the construction industry increased linearly with the increase of the output values per capita

(3) $\beta_{1}<0$ and $\beta_{2}>0, \beta_{3}=0$ signifies that the incomeemissions association took a $\mathrm{U}$-shaped form

(4) $\beta_{1}>0$ and $\beta_{2}<0$ and $\beta_{3}=0$ signifies that the income-emissions association took an inverted U-shaped form

(5) $\beta_{1}<0$ and $\beta_{2}>0, \beta_{3}<0$ signifies that the incomeemissions association took an inverted $\mathrm{N}$-shaped form

(6) $\beta_{1}>0$ and $\beta_{2}<0$ and $\beta_{3}>0$ signifies that the income-emissions association took a $\mathrm{N}$-shaped form

\section{Tapio Decoupling Model}

With different measurement and judgment methods, the decoupling method exists in eight main models thus far [36]. Among these, the elasticity analysis model is an important and effective method with few data requirements, which includes six subcategories of decoupling relationships such as strong decoupling, weak decoupling, recessive decoupling, strong negative decoupling, weak negative decoupling, and expansive negative decoupling. In order to not over interpret slight changes as significant, Tapio put forward the Tapio decoupling model, which has an improvement where a $\pm 20 \%$ variation of the elasticity values around 1.0 are regarded as coupling. From the definition point of view, the Tapio decoupling index is measured as the ratio of percentage change between carbon emissions and GDP during a given time period. Thus, eight logical possibilities are formed to distinguish the decoupling states, as shown in Table 1 . When $\triangle \mathrm{CO}_{2}>0$ and $\triangle I G D P>0$, the smaller $t$ value represents the greater decoupling degree, which means the dependence of the increase between them is weakening. When $\triangle \mathrm{CO}_{2}<0$ and $\triangle I G D P<0$, the bigger $t$ value indicates the greater decoupling degree, which means the dependence of the decrease between them is weakening. When $\triangle \mathrm{CO}_{2}>0$ and $\triangle I G D \mathrm{P}<0$, strong negative decoupling is the worst state that occurs, which means that the economy decreases while carbon emissions increase. On the contrary, When $\triangle \mathrm{CO}_{2}<0$ and $\triangle I G D P>0$, strong decoupling is the most ideal situation, which means that carbon emissions decrease while economics increase.

In this paper, the decoupling elasticity between carbon emissions and economic growth was decomposed into the product of three intermediate variables. That is, the decoupling state between carbon emissions and energy consumption, the decoupling state between energy consumption and the annual construction area, and the decoupling state of the annual construction area to the total output value of 
Table 1. States and detailed explanations of the Tapio decoupling model.

\begin{tabular}{|c|c|c|c|c|}
\hline$t$ & $\Delta \mathrm{CO}_{2}$ & $\triangle I G D P$ & State & Detail explanation \\
\hline$(-\infty, 0]$ & $<0$ & $>0$ & Strong decoupling & Economy increase while carbon emission decrease. \\
\hline$(0,0.8]$ & $>0$ & $>0$ & Weak decoupling & $\begin{array}{l}\text { The increase pace of carbon emission is obviously smaller than } \\
\text { economy. }\end{array}$ \\
\hline$(1.2,+\infty]$ & $<0$ & $<0$ & Recessive decoupling & $\begin{array}{l}\text { The decrease pace of carbon emission is obviously bigger than } \\
\text { economy. }\end{array}$ \\
\hline$(-\infty, 0]$ & $>0$ & $<0$ & Strong negative decoupling & Economy decrease while carbon emission increase. \\
\hline$(0,0.8]$ & $<0$ & $<0$ & Weak negative decoupling & $\begin{array}{l}\text { The decrease pace of carbon emission is obviously smaller than } \\
\text { economy. }\end{array}$ \\
\hline$(1.2,+\infty]$ & $>0$ & $>0$ & $\begin{array}{l}\text { Expansive negative } \\
\text { decoupling }\end{array}$ & $\begin{array}{l}\text { The increase pace of carbon emission is obviously bigger than } \\
\text { economy. }\end{array}$ \\
\hline$(0.8,1.2]$ & $<0$ & $<0$ & Recessive coupling & $\begin{array}{l}\text { The decrease pace of carbon emission is approximately equal to } \\
\text { economy. }\end{array}$ \\
\hline$(0.8,1.2]$ & $>0$ & $>0$ & Expansive coupling & $\begin{array}{l}\text { The increase pace of carbon emission is approximately equal to } \\
\text { economy. }\end{array}$ \\
\hline
\end{tabular}

the construction industry, which are respectively called emissions reduction decoupling, energy decoupling, and value creation decoupling, are formulated as:

$$
\begin{gathered}
t_{C O_{2}, I G D P}=t_{C O_{2}, E C} \times t_{E C, S} \times t_{S, I G D P} \\
=\frac{\Delta C O_{2} / C O_{2}}{\Delta E C / E C} \times \frac{\Delta E C / E C}{\Delta S / S} \times \frac{\Delta S / S}{\Delta I G D P / I G D P} \\
=\left(\Delta C O_{2} / C O_{2}\right) /(\Delta I G D P / I G D P) \\
t_{C O_{2}, E C}=\left(\Delta C O_{2} / C O_{2}\right) /(\Delta E C / E C) \\
t_{E C, S}=(\Delta E C / E C) /(\Delta S / S) \\
t_{S, I G D P}=(\Delta S / S) /(\Delta I G D P / I G D P)
\end{gathered}
$$

...where $t_{C O 2, I G D P}, t_{C O 2, E C}, t_{E C, S}$ and $t_{S, I G D P}$ denote the decoupling elasticity between the carbon emissions and economic growth, emissions reduction decoupling elasticity, energy decoupling elasticity and value creation decoupling elasticity, respectively. $E C$ represents energy consumption. $S$ refers to the annual construction area. $\triangle C O_{2}, \triangle I G D P, \triangle E C$, and $\triangle S$ indicate the change values of each indicator compared with the previous year, respectively.

\section{Results and Discussion}

\section{Construction Industry Carbon Emissions Characteristics in the Low Carbon Pilot Provinces}

There were significant differences in the carbon emissions of the construction industry in the low-carbon pilot provinces. Fig. 1 indicates that the provinces with a higher construction industry carbon emissions and lower carbon intensity were Guangdong and Hubei

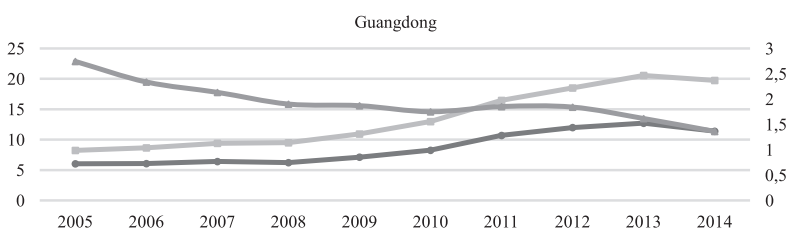

Hubei

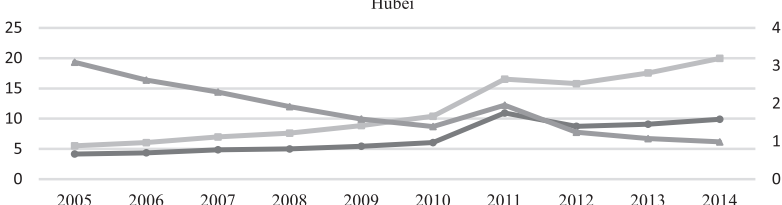

Shannxi
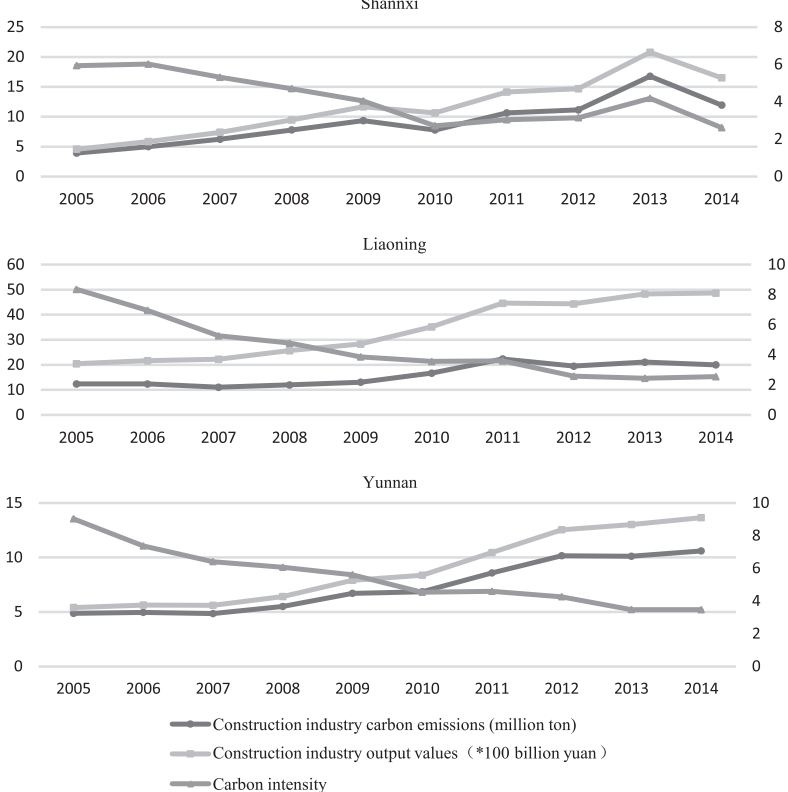

Fig. 1. Construction industry carbon emission characteristics in low-carbon pilot provinces in 2005-2014 
between 2005 and 2014, and that the construction industry carbon emissions were approximately 2 million tons in 2014. The carbon emissions from the construction industry will increase as the development level of economic expansion increases. It is evident that rapid economic expansion is the dominant driving force behind the acceleration of the growth of carbon emissions from the construction industry at this stage. In contrast, Shaanxi and Yunnan, which are located in central China, have a low efficiency level with respect to energy utilization; therefore, the construction industry carbon emissions ranged around 4 million tons. Meanwhile, they had relatively high construction industry carbon intensity. Specifically, construction industry carbon emissions have fluctuated in Liaoning between 2005 and 2014. The primary cause for the reductions is due to technological progress; energy conservation and emissions reduction policies are not effective in this province.

Therefore, as the northwest and central regions including Shaanxi, Liaoning, and Yunnan are located inland, their technical levels and resource utilization, the factors that generally result in high construction industry carbon emissions and high construction industry carbon intensity were relatively low. These results suggest that it is necessary to control environmental problems and enhance carbon emissions efficiency in these regions. In contrast, as the eastern coastal areas such as Guangdong are characterized by high levels of economic development, foreign capital utilization, population quality, energy efficiency, and environmental management standards, they exhibited high construction industry carbon emissions and low construction industry carbon intensity (Fig. 1). Hence, these differences should be considered when developing policies for low-carbon development.

\section{The Relationship between Carbon Emissions and Economic Development in the Construction Industry}

\section{EKC Analysis Results}

Combined with Fig. 2, the inverted N-shaped EKC relationship in the construction industry carbon emissions confirmed the fact that construction industry carbon emissions will show a downward trend with the increase in the IGDP per capita in Guangdong. Furthermore, the decline rate will slow down year by year due to the development of construction technology and the implementation of low-carbon policies. The total construction industry carbon emissions in Guangdong increased along with the increase in per capita IGDP from 2005-2008. At later stages of development, the construction industry carbon emissions significantly increased from 2008-2013 and the total carbon emissions peaked in 2013; however, carbon emissions decreased from 2013-2014. This indicates that the technological progress, energy conservation, and emissions reduction policies of these provinces have made significant achievements.

The curve for Hubei Province, which is located in central China, was an inverted N-shaped EKC relationship in construction industry carbon emissions, which confirmed the fact that construction industry carbon emissions will show a downward trend with the increase in IGDP per capita. From 2005 to 2011, the total construction industry carbon emissions in Hubei Province increased at a relatively rapid rate as the per capita GDP of the industry increased and the growth rate fluctuated; total carbon emissions peaked in 2011; carbon emissions from 2011 to 2012 showed that the total amount decreased with the growth of the industry's per capita GDP; from 2012 to 2014, total carbon emissions increased again, but the growth rate was relatively small, and seemed to enter a relatively stable stage, as presented in Fig. 2.

As presented in Fig. 2, there was an inverted U-shaped EKC relationship in construction industry carbon emissions for Shaanxi Province. The construction industry carbon emissions increased gradually with the increase of the per capita GDP of the industry in Shaanxi Province, but the growth rate slowed down year by year. With the use of clean energy such as solar and the promotion of the concept of green and low-carbon development, construction industry carbon emissions have fallen dramatically. At this time, carbon intensity has stabilized at a relatively low level. Shaanxi Province has achieved results in energy conservation and emissions reduction.

The EKC curve of the construction industry carbon emissions in Liaoning Province has characteristics similar to those in the form of a U-shaped curve and shows that the construction industry carbon emissions increased gradually with the per capita GDP growth of the industry, and the growth rate increased year by year in Liaoning Province. According to the calculation results, it can be estimated that the minimum inflection point of the EKC curve appeared in 2005-2006.

As indicated in Fig. 2, the EKC curve of construction industry carbon emissions in Yunnan Province had characteristics similar to those in the form of an inverted $\mathrm{N}$-shaped curve, which shows that the construction industry carbon emissions increased gradually with the per capita GDP growth of the industry. Yunnan Province is located inland, and its technical levels and resource utilization are relatively low, which results in a single industrial structure.

\section{The Decoupling Effect in Low-Carbon Pilot Provinces}

According to the methodology mentioned in Section 3.3, the decoupling states between the economy and carbon emissions in the construction industry during 2005-2014 could be easily verified. As indicated in Fig. 3, two states - the weak decoupling state and the 

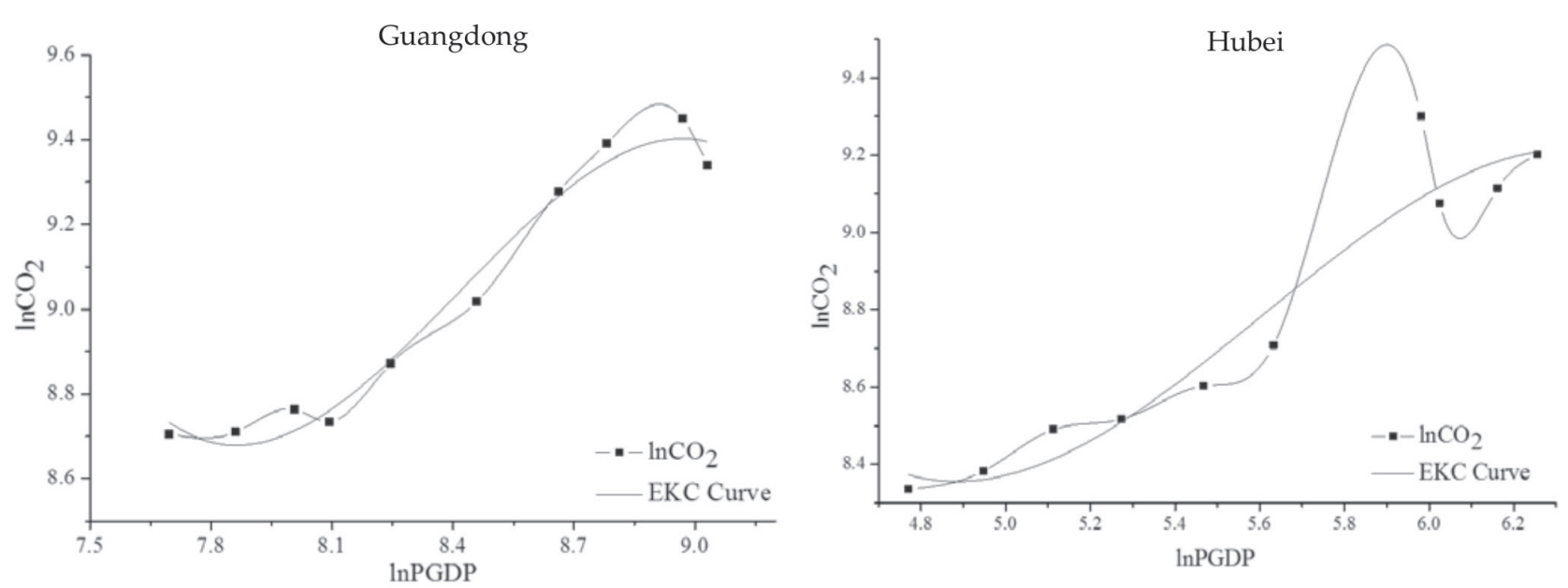

Shaanxi

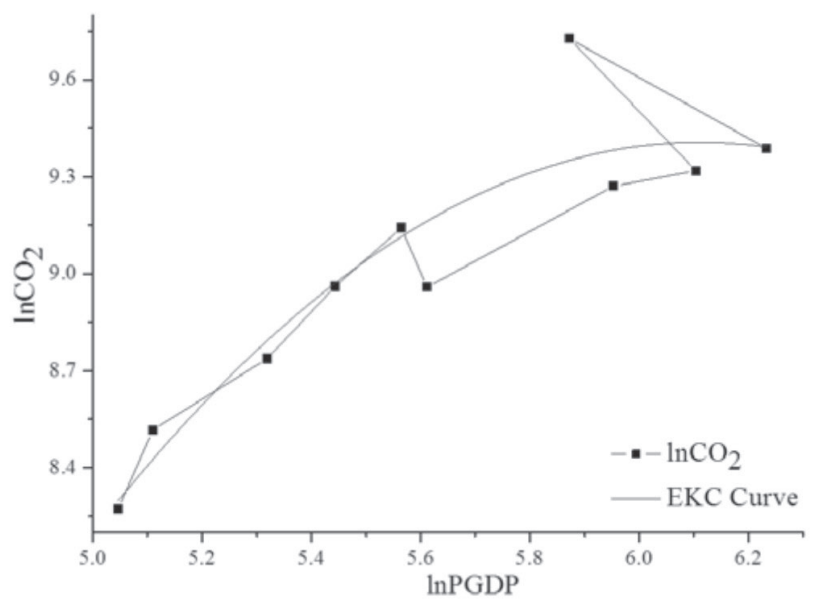

Liaoning

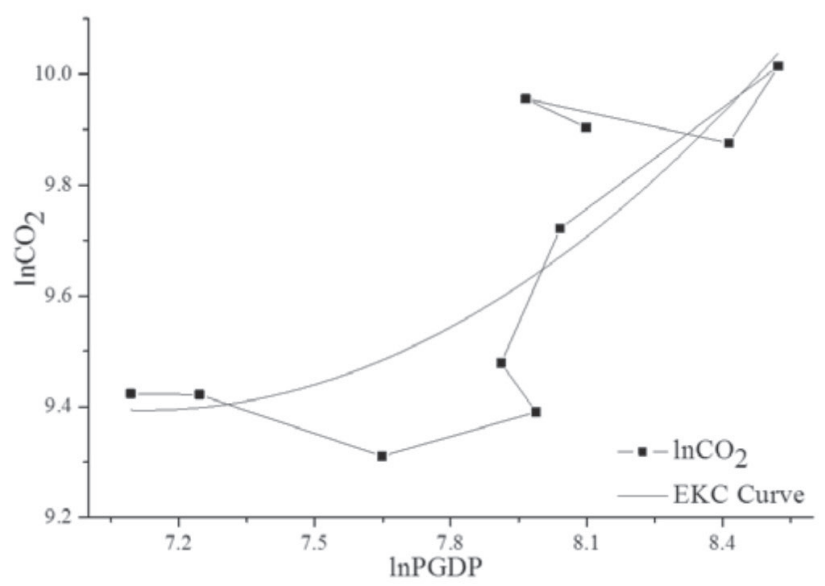

Yunnan

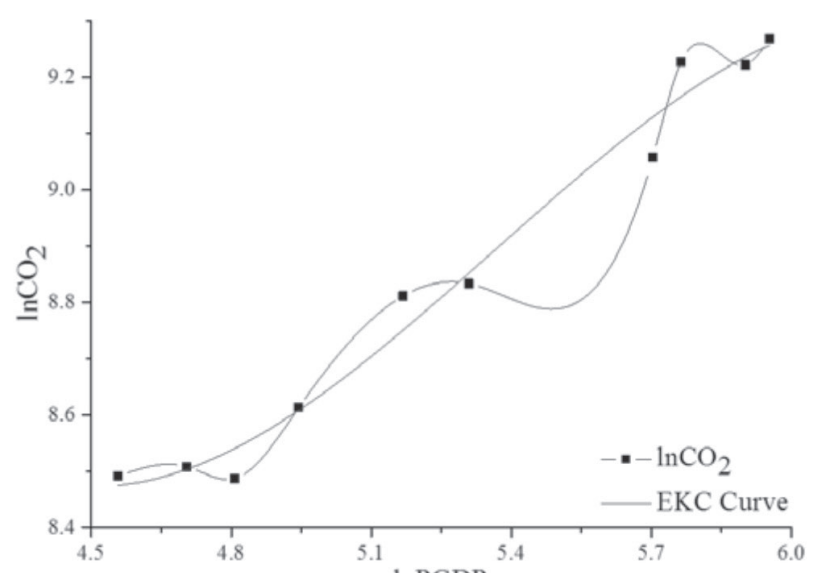

Fig. 2. EKC curve diagram in China's low-carbon pilot provinces.

strong decoupling state - alternated in Guangdong from 2006 to 2014, where the overall situation is ideal. The reason for this phenomenon may be that the current energy savings and emissions reduction effect of the construction industry has had certain remarkable results in Guangdong.

As indicated in Fig. 3, the decoupling states were the weak decoupling state in Hubei Province from
2006 to 2014. It shows that the energy savings and emissions reduction effect of the construction industry has currently had certain remarkable results in Hubei Province. In contrast, Shaanxi, Liaoning and Shandong, which are located in central China, have a low efficiency level with respect to energy utilization; therefore, the decoupling states were not obvious in these provinces from 2006 to 2014 . 


\section{Guangdong}

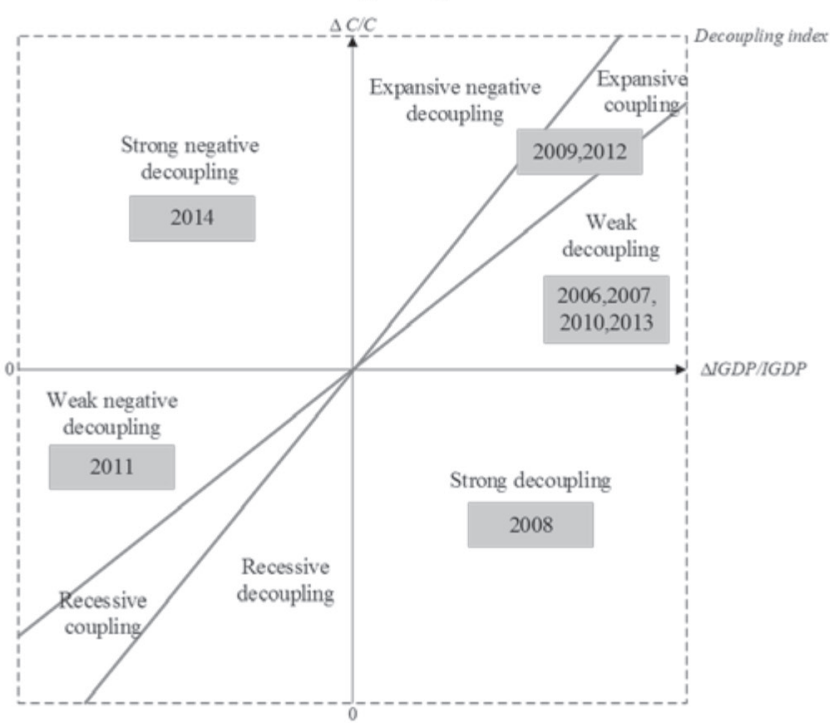

Shaanxi

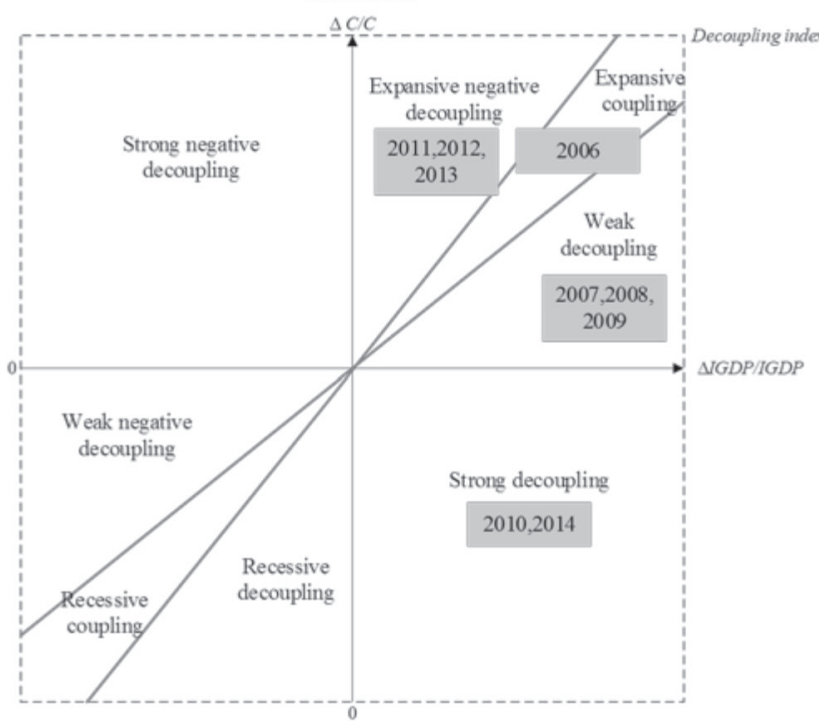

Hubei

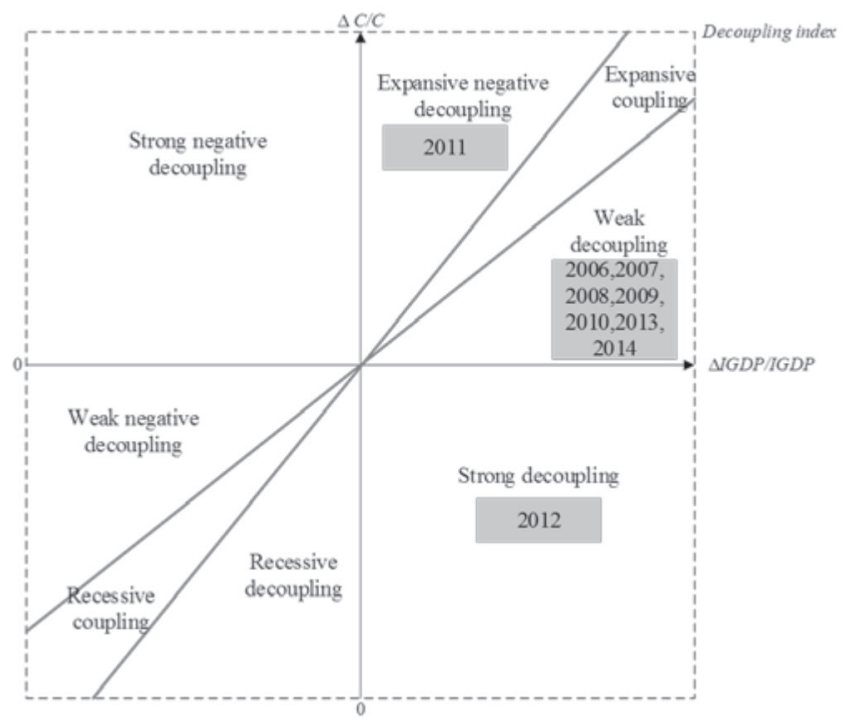

Liaoning

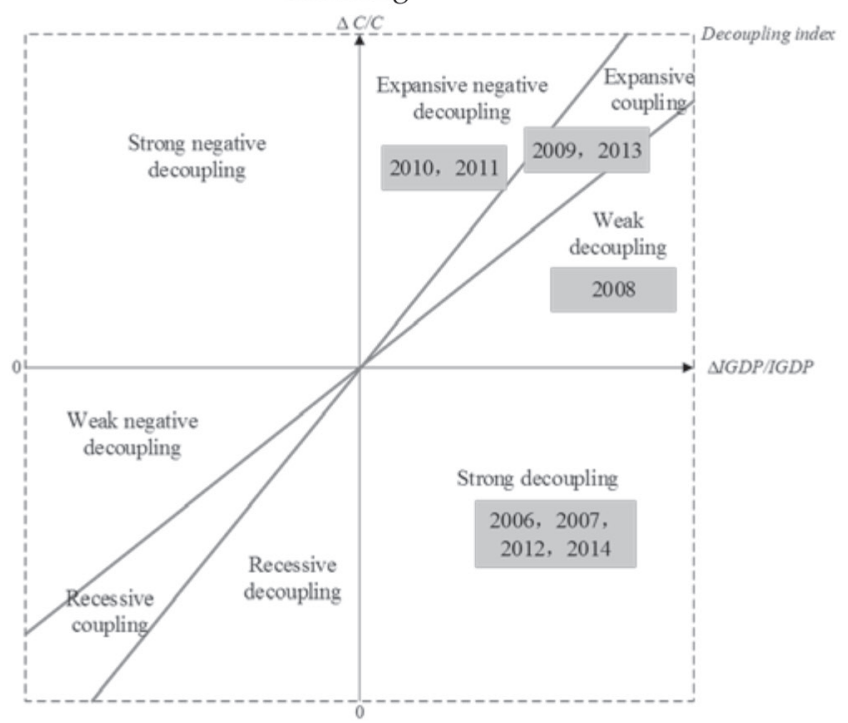

Yunnan

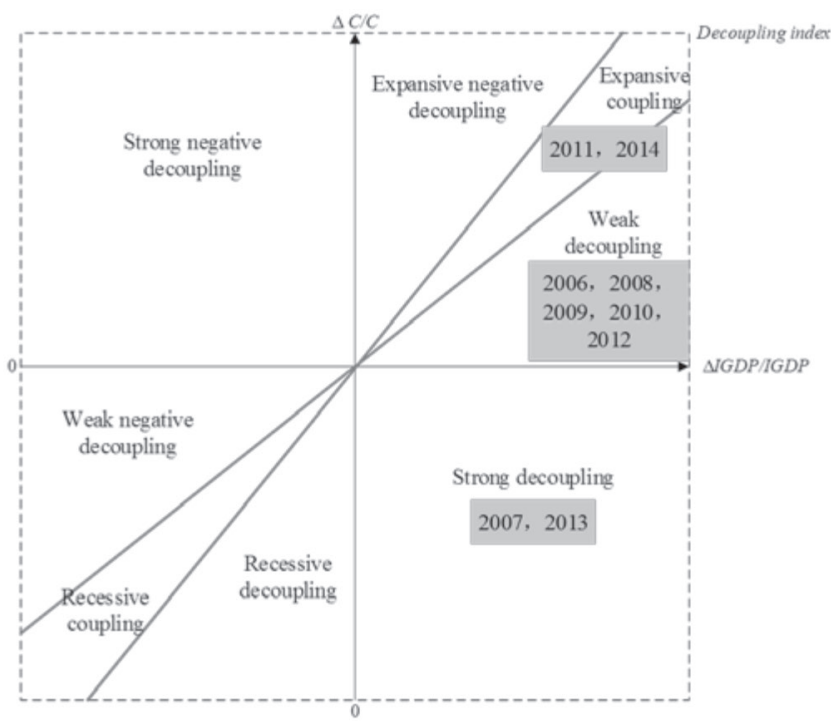

Fig. 3. Overall decoupling status in the low-carbon pilot provinces. 
Table 2. Decoupling states in the construction industry from 2006 to 2014 in Guangdong.

\begin{tabular}{|c|c|c|c|c|c|c|}
\hline Year & $t_{C O 2, E C}$ & Decoupling states & $t_{E C, S}$ & Decoupling states & $t_{S, I G D P}$ & Decoupling states \\
\hline 2006 & 4.4717 & Expansive negative decoupling & 0.0140 & Weak decoupling & 0.4552 & Weak decoupling \\
\hline 2007 & 1.0940 & Expansive coupling & 0.4166 & Weak decoupling & 0.8477 & Expansive coupling \\
\hline 2008 & 0.8136 & Recessive coupling & 0.4595 & Weak negative decoupling & -0.9314 & Strong decoupling \\
\hline 2009 & 0.9174 & Expansive coupling & -24.709 & Strong negative decoupling & -0.0396 & Strong decoupling \\
\hline 2010 & 0.9715 & Expansive coupling & 1.5480 & Expansive negative decoupling & 0.4732 & Weak decoupling \\
\hline 2011 & 0.9681 & Expansive coupling & 1.8890 & Expansive negative decoupling & 0.6821 & Weak decoupling \\
\hline 2012 & 0.9745 & Expansive coupling & 1.0363 & Expansive coupling & 0.9445 & Expansive coupling \\
\hline 2013 & 0.9482 & Expansive coupling & 0.3107 & Weak decoupling & 1.1083 & Expansive coupling \\
\hline 2014 & 0.9308 & Recessive coupling & -6.3972 & Strong decoupling & 0.3320 & Weak decoupling \\
\hline
\end{tabular}

Table 3. Decoupling states in the construction industry from 2006 to 2014 in Hubei.

\begin{tabular}{|c|c|c|c|c|c|c|}
\hline Year & $t_{C O 2, E C}$ & Decoupling states & $t_{E C, S}$ & Decoupling states & $t_{S, I G D P}$ & Decoupling states \\
\hline 2006 & 0.9360 & Expansive coupling & 0.2906 & Weak decoupling & 0.8652 & Expansive coupling \\
\hline 2007 & 1.3692 & $\begin{array}{c}\text { Expansive negative decou- } \\
\text { pling }\end{array}$ & 0.5654 & Weak decoupling & 0.6277 & Weak decoupling \\
\hline 2008 & 0.4005 & Weak decoupling & 0.7499 & Weak decoupling & 0.4595 & Weak decoupling \\
\hline 2009 & 0.6084 & Weak decoupling & 1.2583 & $\begin{array}{c}\text { Expansive negative decou- } \\
\text { pling }\end{array}$ & 0.4550 & Weak decoupling \\
\hline 2010 & 0.7126 & Weak decoupling & 0.7696 & Weak decoupling & 0.8544 & Expansive coupling \\
\hline 2011 & 0.8994 & $\begin{array}{c}\text { Expansive coupling } \\
\text { decoupling }\end{array}$ & 2.5771 & $\begin{array}{c}\text { Expansive negative } \\
0.8671\end{array}$ & Expansive coupling \\
\hline 2012 & 2.2887 & Recessive decoupling & -0.5300 & Strong decoupling & 0.9999 & Expansive coupling \\
\hline 2013 & 1.9089 & $\begin{array}{c}\text { Expansive negative } \\
\text { decoupling }\end{array}$ & 0.0984 & Weak decoupling & 1.1952 & Expansive coupling \\
\hline 2014 & 1.4056 & $\begin{array}{c}\text { Expansive negative } \\
\text { decoupling }\end{array}$ & 0.2779 & Weak decoupling & 1.3475 & $\begin{array}{c}\text { Expansive negative } \\
\text { decoupling }\end{array}$ \\
\hline
\end{tabular}

\section{Decoupling States Analysis of the Different Factors in Low-Carbon Pilot Provinces}

The emissions reduction decoupling state in Guangdong Province maintained expansive coupling from 2006 to 2014 with inefficient emissions reduction technologies. As the decoupling of energy-saving was relatively unstable, the decoupling of value creation was more obvious. Generally speaking, we can take relevant measures to retain its original energy-saving advantages. In addition, increasing the value-creating capabilities of the construction industry's production factors is still the focus of work in Guangdong.

Among them, the emissions reduction decoupling state was not obvious, the energy-saving decoupling state as relatively unstable, and the value creation decoupling state was more obvious. Specifically, energy-saving decoupling was mainly in the weak decoupling state, and value creation elastic decoupling was mainly weak decoupling. Therefore, we can take relevant measures to strengthen the reduction of emissions and further improve construction production in Hubei Province.

The emissions reduction decoupling state in the construction industry kept weak decoupling and expansive decoupling from 2005 to 2014 with relatively little pressure to reduce carbon emissions in Shaanxi Province. Moreover, the energy-saving decoupling state mostly manifested as an expansion of negative decoupling, and the value creation decoupling state appeared with an obvious periodic characteristic of weak decoupling-expansive coupling-expansive negative decoupling. This indicates that Shaanxi Province should increase the production factors of the construction industry, which should focus on the improvement of emissions reduction and energy-saving elastic decoupling.

As presented in Table 5, the emissions reduction decoupling state was expansive coupling, the energysaving decoupling state mostly manifested as an 
Table 4. Decoupling states in the construction industry from 2006 to 2014 in Shaanxi.

\begin{tabular}{|c|c|c|c|c|c|c|}
\hline Year & $t_{C O 2, E C}$ & Decoupling states & $t_{E C, S}$ & Decoupling states & $t_{S, I G D P}$ & Decoupling states \\
\hline 2006 & 1.0576 & Expansive coupling & 1.2692 & Expansive negative decoupling & 0.7819 & Weak decoupling \\
\hline 2007 & 0.9939 & Expansive coupling & 1.0371 & Expansive coupling & 0.6581 & Weak decoupling \\
\hline 2008 & 0.9217 & Expansive coupling & 1.5453 & Expansive negative decoupling & 0.4824 & Weak decoupling \\
\hline 2009 & 0.7648 & Weak decoupling & 1.6298 & Expansive negative decoupling & 0.4697 & Weak decoupling \\
\hline 2010 & 1.1328 & Recessive coupling & -0.8350 & Strong decoupling & 1.0987 & Expansive coupling \\
\hline 2011 & 0.8179 & Expansive coupling & 1.8716 & Expansive negative decoupling & 0.9665 & Expansive coupling \\
\hline 2012 & 1.0461 & Expansive coupling & 0.2404 & Weak decoupling & 15.3775 & Expansive negative decoupling \\
\hline 2013 & 1.1188 & Expansive coupling & 1.6774 & Expansive negative decoupling & 1.5390 & Expansive negative decoupling \\
\hline 2014 & 2.0538 & Recessive coupling & -2.0174 & Strong decoupling & 0.7965 & Weak decoupling \\
\hline
\end{tabular}

Table 5. Decoupling states in the construction industry from 2006 to 2014 in Liaoning.

\begin{tabular}{|c|c|c|c|c|c|c|}
\hline Year & $t_{C O 2, E C}$ & Decoupling states & $t_{E C, S}$ & Decoupling states & $t_{S, I G D P}$ & Decoupling states \\
\hline 2006 & -0.0151 & Expansive coupling & 0.8481 & Expansive negative decoupling & 1.1481 & Weak decoupling \\
\hline 2007 & -0.7814 & Expansive coupling & 1.2838 & Expansive coupling & 0.7017 & Weak decoupling \\
\hline 2008 & 1.7037 & Expansive coupling & 0.7175 & Expansive negative decoupling & 0.3407 & Weak decoupling \\
\hline 2009 & 0.7182 & Weak decoupling & 0.5340 & Expansive negative decoupling & 2.1763 & Weak decoupling \\
\hline 2010 & 1.4971 & Recessive coupling & 0.4802 & Strong decoupling & 1.7074 & Expansive coupling \\
\hline 2011 & 2.2036 & Expansive coupling & 0.4971 & Expansive negative decoupling & 1.3661 & Expansive coupling \\
\hline 2012 & -0.4923 & Expansive coupling & 2.3436 & Weak decoupling & 1.2218 & Expansive negative decoupling \\
\hline 2013 & 1.4969 & Expansive coupling & 0.9666 & Expansive negative decoupling & 0.6088 & Expansive negative decoupling \\
\hline 2014 & 2.7737 & Recessive coupling & -0.1639 & Strong decoupling & 2.3580 & Weak decoupling \\
\hline
\end{tabular}

Table 6. Decoupling states in the construction industry from 2006 to 2014 in Yunnan.

\begin{tabular}{|c|c|c|c|c|c|c|}
\hline Year & $t_{C O 2, E C}$ & Decoupling states & $t_{E C, S}$ & Decoupling states & $t_{S, I G D P}$ & Decoupling states \\
\hline 2006 & 1.2151 & $\begin{array}{c}\text { Expansive negative } \\
\text { decoupling }\end{array}$ & 0.1081 & Weak decoupling & 0.6532 & Weak decoupling \\
\hline 2007 & 0.8926 & Recessive coupling & -0.2910 & Strong decoupling & 0.7325 & Weak decoupling \\
\hline 2008 & 0.9878 & Expansive coupling & 0.8566 & Expansive coupling & 0.8424 & Expansive coupling \\
\hline 2009 & 0.9853 & Expansive coupling & 1.3182 & Expansive negative decoupling & 0.5740 & Weak decoupling \\
\hline 2010 & 1.1700 & Expansive coupling & 0.1448 & Weak decoupling & 0.6086 & Weak decoupling \\
\hline 2011 & 0.9942 & Expansive coupling & 1.3361 & Expansive negative decoupling & 0.7903 & Weak decoupling \\
\hline 2012 & 0.9850 & Expansive coupling & 0.7225 & Weak decoupling & 1.0105 & Expansive coupling \\
\hline 2013 & 1.1682 & Expansive coupling & -0.0282 & Strong decoupling & 0.8243 & Expansive coupling \\
\hline 2014 & 1.0616 & Expansive coupling & 5.6294 & Expansive negative decoupling & 0.1586 & Weak decoupling \\
\hline
\end{tabular}

expansion of negative decoupling, and the value creation decoupling state appeared with an obvious periodic characteristic of weak decoupling-expansive couplingexpansion negative decoupling in Shaanxi Province. This indicates that Shaanxi Province should increase the production factors of the construction industry, which should focus on the improvement of emissions reduction and energy-saving decoupling.

According to Table 6 , the emissions reduction decoupling state basically manifested expansive coupling, which itself is an unsatisfactory state. The energy-saving decoupling state was characterized 
by weak decoupling-expansive coupling-expansion negative decoupling in Yunnan Province, and the value creation decoupling state was based on the weak decoupling and expansive coupling status. Yunnan Province should improve the value creation capabilities of the construction industry, focusing on the improvement of emissions reduction and energy-saving decoupling.

\section{Conclusions and Policy Implications}

This paper presents the relationship between construction industry carbon emissions and economic growth and comparatively analyzed the decoupling of the major influencing factors of carbon emissions in low-carbon pilot provinces during the period 2005 to 2014. These results are positively helpful for analyzing and generating sustainability policy for the government in the development of construction in China.

Through an empirical study of the carbon emissions and economic conditions of the construction industry in low-carbon pilot provinces from 2005 to 2014, the EKC curve was obtained. The existence of an inverted $\mathrm{N}$-shaped EKC curve was visible in Guangdong, Hubei, and Yunnan, while Shaanxi and Liaoning showed inverted U-shaped and U-shaped changes, respectively. The results indicate that the rapid economic expansion is the dominant driving force behind the acceleration of the growth of the carbon emissions of the construction industry at this stage in the coastal provinces such as Guangdong. Provinces such as Shaanxi and Liaoning are located in the northwest and central regions and their technical knowledge and resource utilization are relatively low, so they exhibited an increase in construction industry carbon emissions with their economic growth. These results suggest that policy makers should improve technical knowledge and promote the coordination of economic development and environmental resources according to the characteristics of various provinces. Hence, the existing policies and measures for energy savings and emissions reduction must be steadfastly promoted in order to achieve a further reduction in China's carbon emissions, including financial incentives for energy-saving technological transformation, energy savings assessments for enterprises, and the obligatory targets for provinciallevel energy consumption intensity. Meanwhile, greater effort should be made to exploit emissions reduction potential through the optimization of current energy systems. Particularly, the implementation plan and technology roadmap for realizing China's 2050 renewable energy development goals must be detailed and executed in the near future.

The overall decoupling of construction industry carbon emissions from Guangdong, Hubei, and Yunnan was relatively obvious. There were many years of weak decoupling and strong decoupling, indicating that the construction industry has partially achieved the decoupling target of increasing the IGDP and reducing carbon emissions in China. However, the overall decoupling performances of Shaanxi and Liaoning Provinces were not significant when compared with the other provinces, and there were many unfavorable decoupling situations. The decoupling factors' forces of the various provinces regarding the increase in China's national carbon emissions changed dynamically over time. The main factor of the decoupling state was the value creation decoupling state in Guangdong and Shaanxi. The other factor, the energy-saving decoupling state, hindered the realization of the decoupling of carbon emissions from the construction industry. Accordingly, the energy-saving decoupling state was the main thrust of the decoupling between construction industry carbon emissions and economic growth of Hubei Province and Liaoning Province, where its resistance was the emission reduction decoupling state and value creation decoupling state. As such, reducing energy intensity and optimizing energy structures are critical measures for the sake of achieving the low carbon development goals of different provinces. Energy efficiency should improve in the future by promoting low-carbon technologies and promoting and applying energy-efficient equipment. In addition, improving the usage frequency and scope of clean energy (natural gas, hydropower, solar energy, and wind energy) could effectively inhibit the economic growth effect on construction industry carbon emissions. These results suggest that the driving factors of carbon emissions decoupling are energy-savings and value creating a decoupling state in low-carbon pilot provinces, while the emissions reduction decoupling state was common resistance in the provinces. Overall, the driving forces behind the carbon emissions of the construction industry in various provinces differed greatly among each other and changed dynamically over time. Accordingly, the important problem regarding the future development of China is to coordinate the relationship between economic growth and carbon emissions. In addition, in order to reduce carbon emissions, the promotion of lowcarbon building technology and the reduction of high carbon consumption with respect to building materials are essential according to the characteristics of each province.

Moreover, it should be noted that when considering provincial differences in the relationship between economic growth and construction industry carbon emissions, the government plays an extremely significant role in the construction industry development with low-carbon emissions. Therefore, the formulation of the government's emissions reduction strategies should consider both the features of provincial carbon emissions and the underlying forces shaping those features. Accordingly, these strategies must be refined in a timely manner in order to respond appropriately to the different developmental stages. 


\section{Acknowledgements}

The research work was supported by the National Social Science Foundation of China [Grant No. 16CJY028].

\section{Conflict of Interest}

The authors declare no conflict of interest.

\section{References}

1. CHUAI X., HUANG X., LU, Q., ZHANG M., ZHAO R., LU J. Spatiotemporal changes of built-up land expansion and carbon emissions caused by the Chinese construction industry. Environmental Science \& Technology. 49, 13021, 2015. https://doi.org/10.1021/acs.est.5b01732

2. CHEN J.D., SHEN L.Y., SONG X.N., SHI Q., LI S.P. An empirical study on the $\mathrm{CO} 2$ emissions in the Chinese construction industry. Journal of Cleaner production. 168, 654, 2017. https://doi.org/10.1016/j.jclepro.2017.09.072

3. MENYAH K., WOLDE-RUFALE Y. Energy consumption, pollutant emissions and economic growth in South Africa. Energy Economics. 32 (6), 1374, 2010. https://doi. org/10.1016/j.eneco.2010.08.002

4. ANDREONI V., GALMARINI S. Decoupling economic growth from carbon dioxide emissions: A decomposition analysis of Italian energy consumption. Energy. 44, 682, 2012. https://doi.org/10.1016/j.energy.2012.05.024

5. ZHANG M., WANG W.W. Decouple indicators on the $\mathrm{CO}_{2}$ emission-economic growth linkage: the Jiangsu Province case. Ecological Indicators. 32, 239, 2013. https://doi. org/10.1016/j.ecolind.2013.03.033

6. NIU S.W., LIU Y.Y., DING Y.X., QU W. China's energy systems transformation and emissions peak. Renewable \& Sustainable Energy Reviews. 58, 782, 2016. https://doi. org/10.1016/j.rser.2015.12.274

7. JIANG J., YE B., XIE D., TANG J. Provincial-level carbon emission drivers and emission reduction strategies in China: Combining multi-layer LMDI decomposition with hierarchical clustering. Journal of Cleaner Production. 169, 178, 2017. https://doi.org/10.1016/j.jclepro.2017.03.189

8. SUN L.C., WANG Q.W., ZHOU P., CHENG F.X. Effects of carbon emission transfer on economic spillover and carbon emission reduction in China. Journal of Cleaner Production. 112, 1432, 2016. https://oi.org/10.1016/j. jclepro.2014.12.083

9. CAI J.L., YIN H., VARIS O. Impacts of industrial transition on water use intensity and energy-related carbon intensity in China: a spatio-temporal analysis during 2003-2012. Applied Energy. 183, 1112, 2016. https://doi. org/10.1016/j.apenergy.2016.09.069

10. WANG Y., ZHAO T. Impacts of energy-related $\mathrm{CO}^{2}$ emissions: evidence from under developed, developing and highly developed regions in China. Ecological Indicators. 50, 186, 2015.

11. ZHANG H.W., ZHANG S.Y., SHI L.Y. The comparative study of China's low carbon pilot provinces $\mathrm{CO}_{2}$ emission characteristics and influence factors. Resources and Sustainable Development. 734, 1948, 2013. https://doi. org/10.4028/www.scientific.net/AMR.734-737.1948
12. CHEN H., CHEN W.Y. Carbon mitigation of China's building sector on city-level: Pathway and policy implications by a low-carbon province case study. Journal of Cleaner Production. 224, 207, 2019. https://doi. org/10.1016/j.jclepro.2018.12.022

13. FENG J.C., ZHENG X.L., YU Z., TANG S., LI W.C., XU W.J. Status and Driving Forces of $\mathrm{CO}_{2}$ Emission of the National Low Carbon Pilot: Case Study of Guangdong Province during 1995-2015. Innovative Solutions for Energy Transitions. 158, 3602, 2019. https://doi. org/10.1016/j.egypro.2019.01.904

14. PARESH K.N., BEHNAZ S., ABDORREZA S. Economic growth and carbon emissions. Economic Modelling. 53, 388, 2016.

15. GROSSMAN G.M., KRUEGER A.B. Environmental impacts of a North American free trade agreement. Social Science Electronic Publishing. 8 (2), 223, 2000. https://doi. org/10.3386/w3914

16. LIU Z., GENG Y., LINGNER S., ZHAO H.Y., FUJITA T., GUAN D.B. Embodied energy use in China's industrial sectors. Energy Policy. 49, 751, 2012. https://doi. org/10.1016/j.enpol.2012.07.016

17. OZTURK I., ACARAVCI A. $\mathrm{CO}_{2}$ emissions, energy consumption and economic growth in Turkey. Renewable \& Sustainable Energy Reviews. 14, 3220, 2010. https://doi. org/10.1016/j.rser.2010.07.005

18. SHAHBAZ M., FARHANI S., OZTURK I. Do coal consumption and industrial development increase environmental degradation in China and India? Environmental Science and Pollution Research. 22 (5), 3895, 2015. https://doi.org/10.1007/s11356-014-3613-1

19. ANG J.B. Economic development, pollutant emissions and energy consumption in Malaysia. Journal of Policy Modeling. 30, 271, 2008. https://doi.org/10.1016/j. jpolmod.2007.04.010

20. ZHANG X.P., CHENG X.M. Energy consumption, carbon emissions, and economic growth in China. Ecological Economics. 68, 2706, 2009. https://doi.org/10.1016/j. ecolecon.2009.05.011

21. CHINDO S., ABDULRAHIM A., WAZIRI S.I., HUONG W.M., AHMAD A.A. Energy consumption, $\mathrm{CO}_{2}$ emissions https://doi.org/10.1007/s10708-014-9558-6

22. ALBIMAN M.M., SULEIMAN N.N., BAKA H.O. The relationship between energy consumption, $\mathrm{CO}_{2}$ emissions and economic growth in Tanzania. International Journal of Energy Sector Management. 9, 361, 2015. https://doi. org/10.1108/IJESM-05-2014-0006

23. PAK S., LEE Y. Regional model of EKC for air pollution: evidence from the Republic of Korea. Energy Policy. 39, 5840, 2011. https://doi.org/10.1016/j.enpol.2011.06.028

24. LIU L. Environmental poverty, a decomposed environmental Kuznets curve, and alternatives: sustainability lessons from China. Ecological Economics. 73, 86, 2011. https://doi.org/10.1016/j.ecolecon.2011.10.025

25. OECD (Organization for Economic Co-operation and Development). Indicators to Measure Decoupling of Environmental Pressure from Economic Growth. OECD, Paris, 2002.

26. VEHMAS J., LUUKKANEN J., KAIVO-OJA J. Linking analyses and environmental Kuznets curves for aggregated material flows in the EU. Journal of Cleaner Production. 15(17), 1662, 2007. https://doi.org/10.1016/j. jclepro.2006.08.010

27. TAPIO P. Towards a theory of decoupling: degrees of decoupling in the EU and the case of road traffic in Finland 
between 1970 and 2001. Transport Policy. 12, 137, 2005. https://doi.org/10.1016/j.tranpol.2005.01.001

28. LUKEN R.A., PIRAS S. A critical overview of industrial energy decoupling programs in six developing countries in Asia. Energy Policy 39, 3869, 2011. https://doi. org/10.1016/j.enpol.2011.04.029

29. WANG W.W., LIU R., ZHANG M. Decomposing the decoupling of energy related $\mathrm{CO}_{2}$ emission and economic growth in Jiangsu Province. Energy for Sustainable Development. 17, 62, 2013. https://doi.org/10.1016/j. esd.2012.11.007

30. REN S. G., YIN H.Y., CHEN X.H. Using LMDI to analyze the decoupling of carbon dioxide emissions by China's manufacturing industry. Environmental Development. 9, 61, 2014. https://doi.org/10.1016/j.envdev.2013.11.003

31. LI Y., DU Q., WU J., HAN X. Relationship between the development and $\mathrm{CO} 2$ emissions of transport sector in China. Transportation Research Part D: Transport and Environment. 74, 1, 2019. https://doi.org/10.1016/j. $\operatorname{trd}$.2019.07.011

32. YUAN B., REN S., CHEN X. The effects of urbanization, consumption ratio and consumption structure on residential indirect $\mathrm{CO}_{2}$, emissions in China: A regional comparative analysis. Applied Energy. 140, 94, 2015. https://doi.org/10.1016/j.apenergy.2014.11.047

33. KANG Y.Q., ZHAO T., WU P. Impacts of energy-related $\mathrm{CO}_{2}$, emissions in china: a spatial panel data technique. Natural Hazards. 81(1), 405, 2016. https://doi.org/10.1007/ s11069-015-2087-x

34. ZHOU S., WANG Y., YUAN Z., OU X. Peak energy consumption and $\mathrm{CO}_{2}$ emissions in china's industrial sector. Energy Strategy Reviews. 20, 113, 2018. https://doi. org/10.1016/j.esr.2018.02.001

35. JIANG R., ZHOU Y.L., LI R.R. Moving to a Low-Carbon Economy in China: Decoupling and Decomposition Analysis of Emission and Economy from a Sector Perspective. Sustainability. 10(4), 978, 2018. https://doi. org/10.3390/su10040978

36. ZHONG T.Y., HUANG X.J., HAN L., WANG B.Y. Review on the research of decoupling analysis in the field of environments and resource. Journal of Natural Resources. 25, 1400, 2010. 
